\title{
Assessing the Impact of Innovation Activity on Mining Industry Results
}

\author{
Oleg Kalenov ${ }^{1, *}$, Sergey Kukushkin ${ }^{1}$, and Galina Bolkina ${ }^{1}$ \\ ${ }^{1}$ Plekhanov Russian University of Economics, 117997, Moscow, 36 Stremyanny lane, Russia
}

\begin{abstract}
The role of the mining industry in the world economy is enormous, since its branches are the most important source of industrial raw materials, without which the intensive growth of modern industry would be completely impossible. However, the technologies used in it are not always innovative. Despite the fact that the mining industry occupies a fairly small percentage in the structure of the world economy and does not exceed $10 \%$, it is an important source of income for many states, including Russia. However, the changes that are now observed in the global economy require new approaches to organizing activities. Despite its profitability, this industry is quite difficult to manage. The way from the extraction of raw materials to their end user is very complicated and depends on many conditions. For the successful integration of the Russian mining industry into new economic realities, it is necessary to intensify innovative processes by investing financial resources in new equipment and high technology. At the same time, acceleration of the development of the mining industry can be achieved in the chain "mining industry processing industry" through the introduction and use of nanotechnology, which can significantly improve the quality of raw materials.
\end{abstract}

\section{Introduction}

One of the key tasks facing Russia is to enter a qualitatively new development path, which is based on the transition from a raw material orientation of the economy to an innovative and technological one. The situation in the oil market, characterized by a fall in oil prices and a reduction in its production, only confirms this need. If the manufacturing industry has enough serious groundwork for the implementation of the innovative leap, then most sectors of the mining industry cannot realize this yet. Its constituent industries belong to the primary sector of the economy and, as a rule, are characterized by low-tech production. However, this does not mean that they lack innovative potential; it just requires a deeper approach for its implementation. The results of the mining industry directly depend not only on the volume of investments in the industry, but also on the effectiveness of their use, on the correct approach to the investments' development.

\footnotetext{
* correspondent author: oekalenov@yandex.ru
} 


\section{Materials and Methods}

The methodology for analyzing and evaluating the economic and innovative development of industry is based on the concepts of the innovative economy development, outlined by J. Schumpeter [1], B. Lundvall [2], S. Glazyev [3], F. Agafonov [4], O. Borisova [5], T. Skryl [6], O. Milyushenko [7]. The problems of the mining industry development, including the regional level, are considered in the works of M. Anastasov [8], E. Dotsenko [9], V. Frolova [10], O. Ivanenko [11].

To assess the impact of innovative costs on the development of the mining industry, it is necessary:

- to study the dynamics of costs amount for product and process innovations;

- to compare the amount of costs for technological innovation and the volume of production of extractive industries;

- to correlate the costs of acquiring machinery and equipment, the costs of research and development and the volume of production of extractive industries;

- to evaluate their growth rates by using the basic and chain coefficient method.

It is the analysis of the above indicators that will help to understand the main trends in the mining industry and determine its prospects in the transition to the innovative development path.

\section{Results and Discussion}

Extractive industries belong to the primary sector of economy, which also includes agriculture, fisheries and forestry. These types of activities do not directly create economic benefits for personal consumption; their products act as intermediate products. Therefore, the results of the organizations' activities in these industries largely depend on the situation on the markets for the final product. They do not have the ability to generate their income by increasing added value. In many respects, the effectiveness of their activities depends on the volatility of raw material prices and the scale of activity - production volumes.

In the extractive industries, radical (breakthrough) innovations are not being developed; therefore, these types of activities do not act as a source of development of the national economy. As a rule, in these sectors the revolutionary innovations of the current technological order exert their influence indirectly, through the innovative products of a higher technological redistribution.

Innovative activity in these sectors has its own characteristics. Innovation in them mainly affects processes, not manufactured products. As can be seen from the graph (Fig. 1), the cost of process innovation is several times greater than the cost of product innovation. Basically, organizations in the extractive industries acquire machinery and equipment. In addition, process innovations include:

- the development of environmentally friendly, ecological technologies;

- the methods (ways) of extraction of raw materials from "inconvenient" and inefficient deposits;

- the methods of more efficient development of deposits.

Over the period from 2003 to 2017, the production of extractive industries increased several times (Fig. 2). If the volume of production of these industries in 2003 amounted to 773095.4 million rubles, then in 2017 it amounted to 12549926 million rubles. The production of fuel and energy enterprises in 2003 amounted to 688727 million rubles, in 2017 - 9989506 million rubles. Over the same period, extractive industry enterprises without fuel and energy products produced 84368.4 and 2560,420 million rubles respectively. The increase in the volume of activity in these sectors was significantly influenced by the world market prices, but the increase in production also played an 
important role. So, if the coal industry produced 256 million tons in 2003, then in 2017 386 million tons, exceeding the 1991 production by 33 million tons. In many ways, the increase in demand for coal, and, consequently, its production, was influenced by rising prices for crude oil and natural gas in the world market.

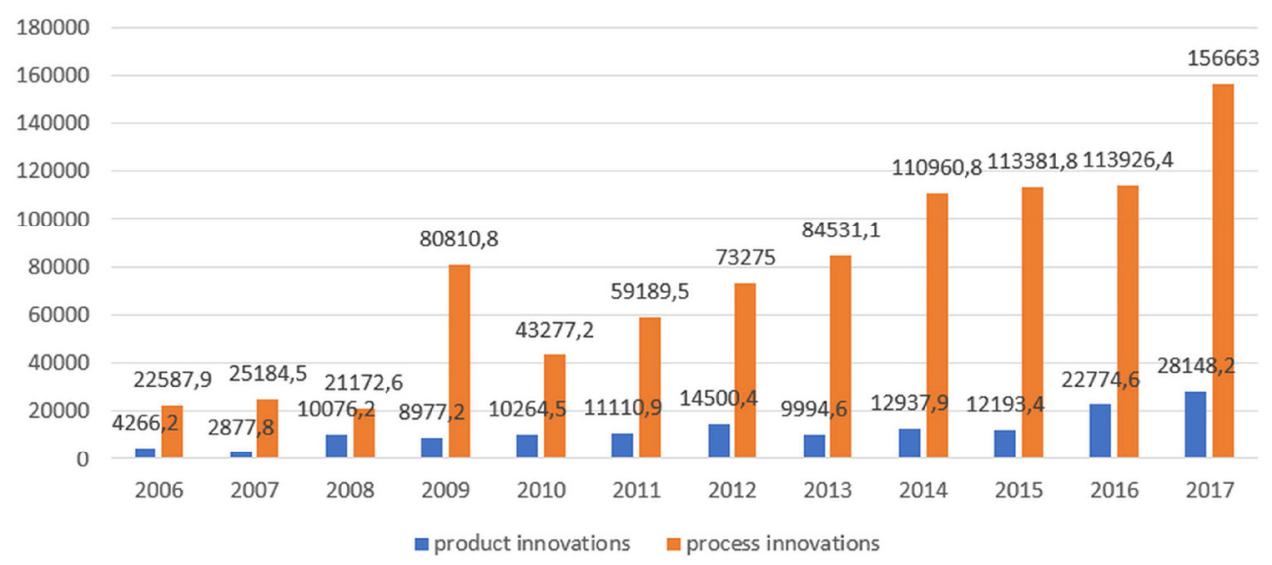

Fig. 1. Costs of product and process innovations (million rubles) [12].

Over the analyzed period, the costs of technological innovations at mining enterprises increased (Fig. 2). If in 2003 enterprises spent 8539.4 million rubles, then in 2017 184811.2 million rubles. In 2003, enterprises of the fuel and energy industries spent 7383.6 million rubles for technological innovations, and 184814.8 million rubles in 2017. Of this block, the lowest costs for technological innovations were borne by coal mining enterprises - 113.8 million rubles in 2017, enterprises extracting ore materials provided 1,155.8 million rubles for technological innovations and 19996.6 million rubles respectively.

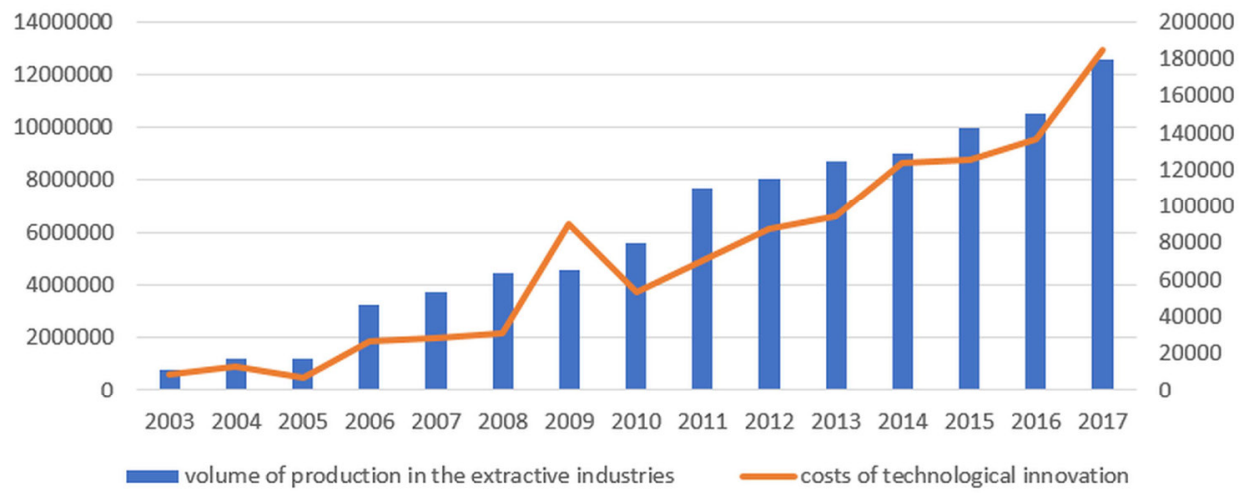

Fig. 2. Schedule comparing costs of technological innovation and volume of production in the extractive industries (million rubles) [12].

The enterprises of these industries for the analyzed period slightly increased the costs of technological innovation relative to the results of their activities. Therefore, if in 2003 they spent $1.1 \%$ on this type of innovation in relation to the volume of products sold, then in 2017 this share amounted to only $1.47 \%$, i.e. an increase of $0.37 \%$. Although there were years when these costs increased. Therefore, in 2009 they amounted to almost 2\%. This may not be due to the strategic priorities, but to the world prices for minerals. 
In the costs of technological innovation in the analyzed period, the main share was the cost of purchasing machinery and equipment and the costs associated with research and development. So, for example, in the coal industry, the cost of acquiring machinery and equipment in the analyzed period amounted to more than $90 \%$.

In the analyzed period, the costs of research and development and the purchase of machinery and equipment were distributed unevenly. Until about the middle of the period (2009), these costs were comparable, but in 2009 there was a sharp increase in research and development costs, after which they decreased and remained at the level of previous years. The costs for the purchase of machinery and equipment increase in 2010, and after that their share is constantly growing (Fig. 3). They repeat the curve of the dynamics of sales of mining products.

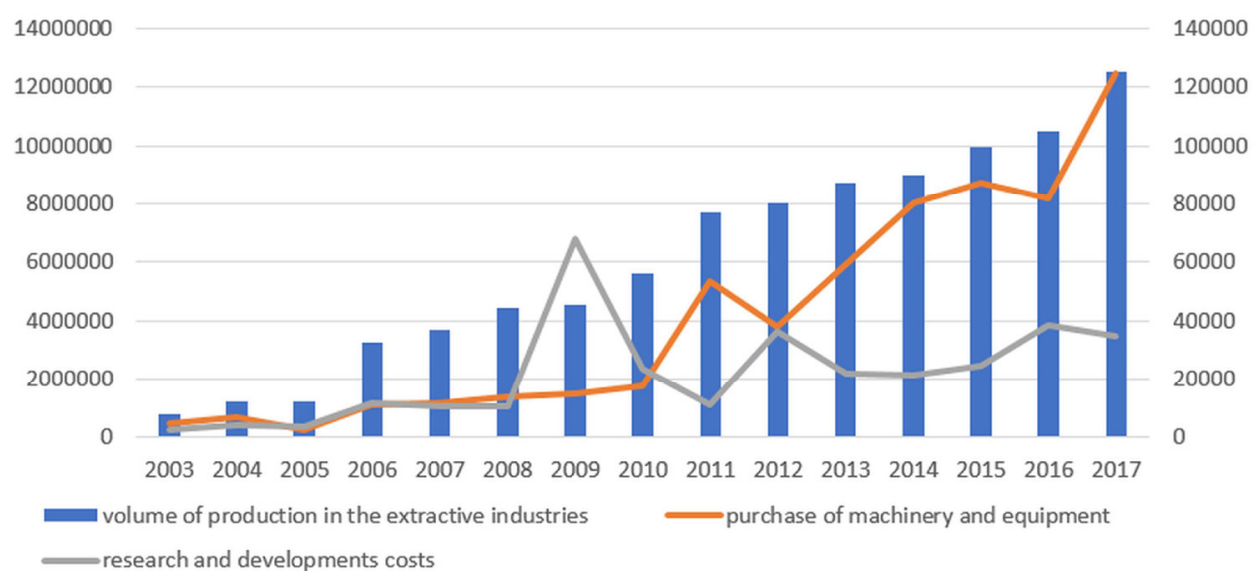

Fig. 3. Schedule comparing the expenditures on purchase of machinery and equipment, the research and development costs and volume of production in the extractive industries (million rubles) [12].

A comparison of the growth rate of expenditures on technological innovations and the production rate confirms the conclusion that the share of these costs is constant, with the exception of 2009. The dynamics of expenditures on technological innovations begins to change in 2013. It begins to leave behind the pace of production (Fig. 4). The same trend is confirmed by the growth rate of expenses for the purchase of machinery and equipment (Fig. 5).

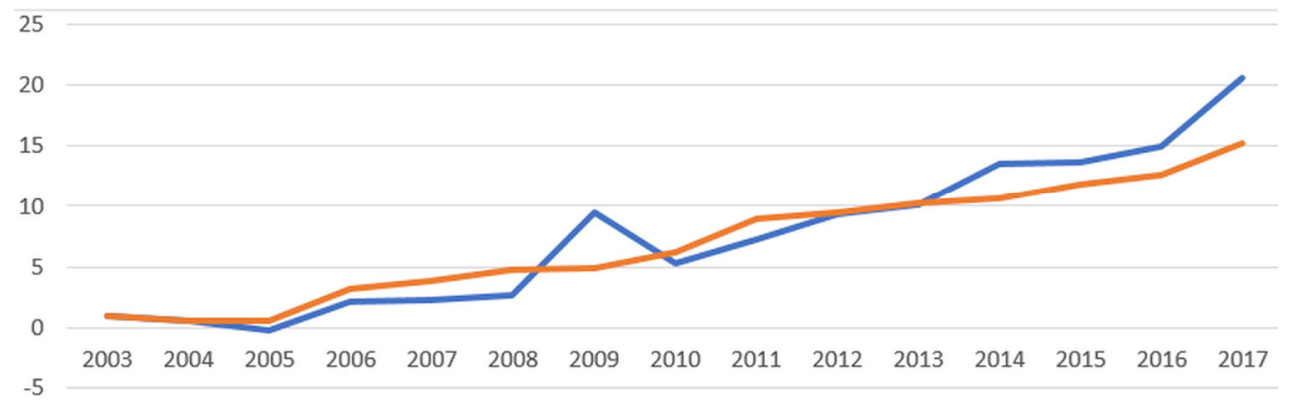

growth rate of expenditures on technological innovations

growth rate of output extractive industries

Fig. 4. Comparison of growth rate of expenditures on technological innovations and growth rate of output in the extractive industries [12]. 


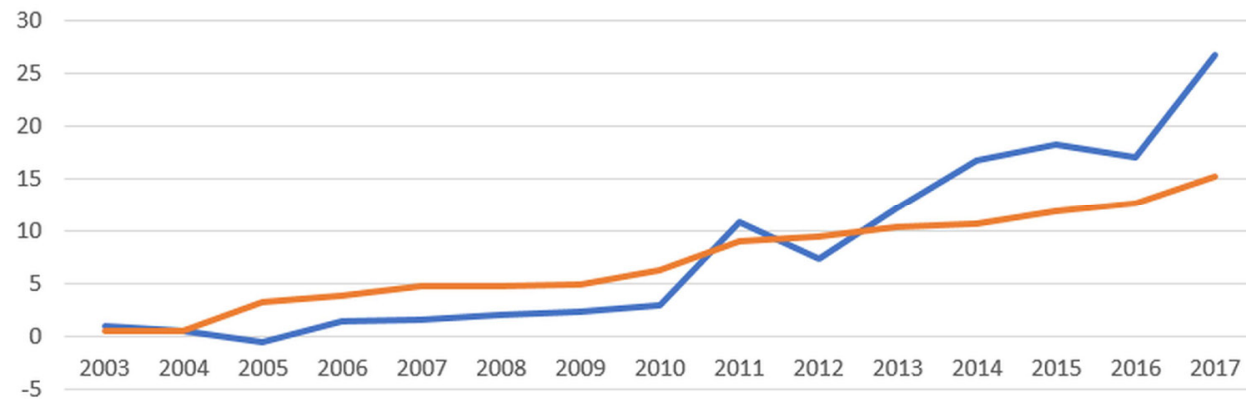

growth rate of expenses for the purchase of machinery and equipment
growth rate of output extractive industries

Fig. 5. Comparison of growth rate of expenses for the purchase of machinery and equipment and growth rate of output in the extractive industries [12].

To conduct a more detailed analysis of growth rates, we use the chain coefficient method. The growth rate of production volumes for the analyzed period is uniform. The exception is 2006, and starting in 2012, they become uniform with a slight increase (Fig. 6). The growth rate of costs for technological innovation shows us a different dynamic. For the analyzed period, we see that in 2006 and in 2009, there was a sharp increase in these costs. If the increase in costs in 2006 can be explained by the increased financial capabilities of extractive enterprises, then the leap in 2009 can only be associated with an increase in prices for services and technical equipment associated with innovative processes and a somewhat belated reaction to the Great Recession. In the same period, we observe two sharp drops in the growth rates - 2005 and 2010. During these years, growth rates were negative: -0.47 and -0.4 , respectively. The slowdown in 2005 was due to a sharp decline in the performance of mining enterprises. The growth rate this year was $2 \%$ compared with $54.7 \%$ in the previous 2004. The negative value of the growth rate of costs for technological innovation in 2010 is associated with overcoming the consequences of the global economic crisis.

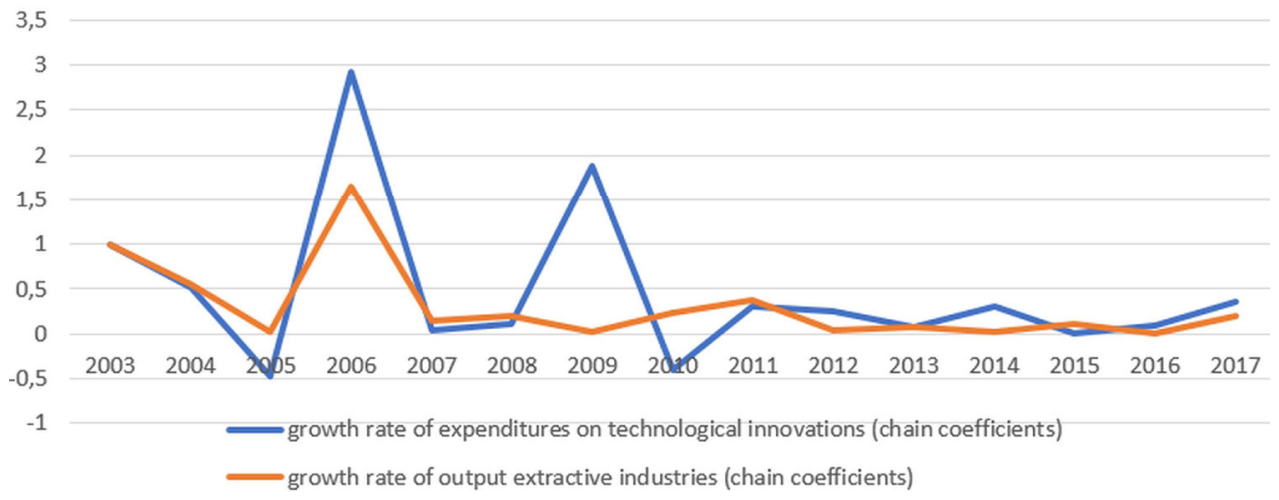

Fig. 6. Comparison of growth rate of expenditures on technological innovations and growth rate of output in the extractive industries (chain coefficients) [12].

We observe a slightly different dynamics with the growth rate of expenses for the purchase of machinery and equipment (chain coefficients). Until 2007, they accurately repeat the growth rate of expenditure on technological innovations - a sharp increase in 2006 and a sharp decrease (to negative) in 2005. After 2007, the growth rate of expenses for the purchase of equipment behave differently. Until 2010, they fully coincide with the output growth rate, in 2011 there is a sharp jump - from 0.18 to 2.03. The next year, again, 
the fall to negative (-0.29), and in 2013 the "mirror" jump - 0.57. After that, a smooth decline and a sharp increase in 2017 were observed for three consecutive years (Fig. 7).

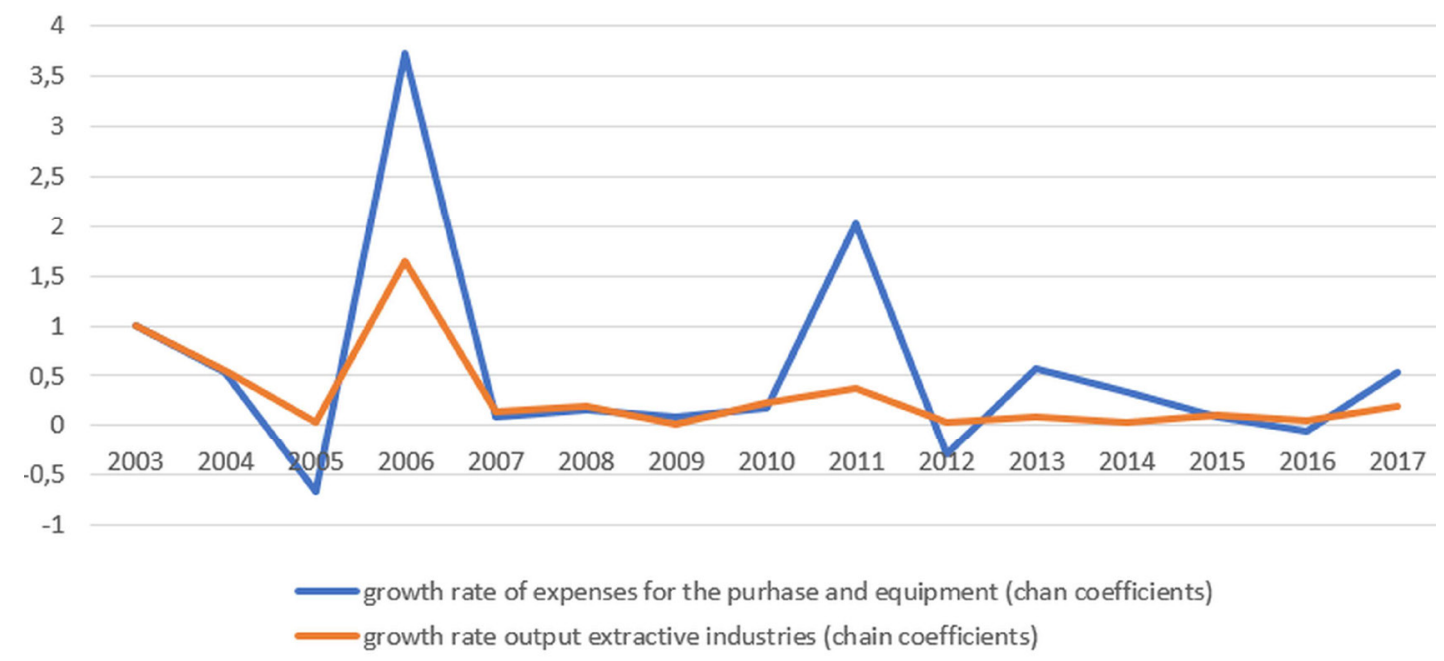

Fig. 7. Comparison of growth rate of expenses for the purchase of machinery and equipment and output growth rate in extractive industries (chain coefficient) [12].

We can pay attention to one more feature. Since 2012, an increase in the expenses for the purchase of machinery and equipment seems to precede an increase in output growth rates. This may indicate that the policy of technical re-equipment of mining enterprises has become more purposeful than before.

\section{Conclusion}

It is obvious that today the extractive industries are not breakthrough ones. In this regard, the results of their activities will depend on the results of the activities of processing enterprises, which are realized in machinery and equipment, as well as technical means for geological exploration. The analysis shows that the expenses on research and development in the mining industry are directed more towards the exploration of new deposits, which, accordingly, may affect the results in future periods. Moreover, the short-term results of operations of enterprises in the extractive industries are primarily affected by the expenses associated with the purchase of machinery and equipment. They account for more than $50 \%$ of innovation costs, and in the coal industry, these costs account for more than $90 \%$. Accelerating the development of extractive industries can be activated in the chain "extractive industry - processing industry" through the introduction and use of nanotechnology, which will improve the quality of raw materials. An especially large effect can be achieved in the field of iron ore and coal mining.

\section{References}

1. J. Schumpeter, The theory of economic development (Progress, Moscow, 1982).

2. B. Lundvall, Nation system of innovation.Towards atheory of innovation and interactive learning (Pinter Publishers, London, 1992)

3. S. Glazyev, The economic theory of technical development (Science, Moscow, 1990) 
4. F. Agafonov, A. Genin, O. Kalinina, O. Brel , O. Zhironkina, E3S Web Conf., 15, 04011 (2017)

5. O. Borisova, V. Frolova, L. Artamonova, E3S Web Conf., 105, 04047 (2019)

6. T. Skryl, E. Shavina, E. Dotsenko, E3S Web Conf., 105, 04049 (2019)

7. O. Miliushenko, A. Kovalev, M. Zhidkova, E3S Web Conf., 105, 04046 (2019)

8. M. Anastasov, N. Kazitskaya, I. Politkovskaya, E3S Web Conf., 105, 04043 (2019)

9. E. Dotsenko, N. Ezdina, E3S Web Conf., 15, 04012 (2017)

10. V. Frolova, O. Dolina, T. Shpilkina, E3S Web Conf., 105, 01054 (2019)

11. O. Ivanenko, E3S Web Conf., 105, 04025 (2019)

12. Official site of the Federal State Statistics Service of the Russian Federation. URL: http://www.gks.ru/ 